\title{
Overly ambitious attempt to reform health care
}

\author{
Care of the Soul in Medicine: \\ Healing Guidance for Patients, Families, \\ and the People Who Care for Them \\ Thomas Moore \\ Hay House; 2010.
}

$\mathrm{T}$ he state of health care at the beginning of the 21 st century has been widely lamented. Despite advances in treatments and technology, many authors have expressed concern that medicine has become focused on a scientific understanding of illness and humanistic values are being neglected. Thomas Moore's latest book adds another voice to that chorus.

Moore will be known to many as the author of the runaway bestselling Care of the Soul, as well as Dark Nights of the Soul, The Soul of Sex and The Soul's Religion among other titles. $\mathrm{He}$ is a psychotherapist with a background in theological studies who draws his ideas from Jungian concepts and a variety of religious traditions.

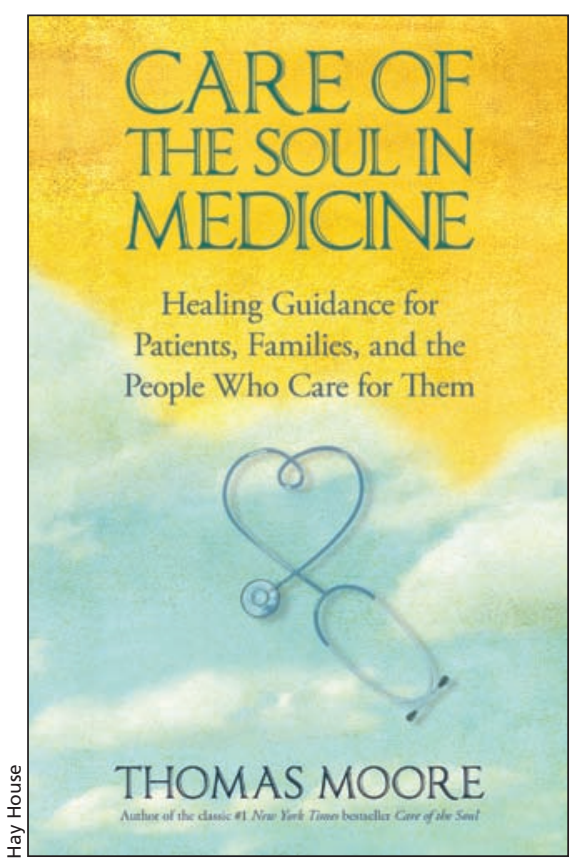

covering. Taking it on seems a bit of a departure for Moore, whose previous books have tended to be more philosophical, contemplative and mystical.

Care of the Soul in Medicine is very

\section{Moore often disapproves of how we treat our patients and each other.}

Anyone who has read his previous writings will be familiar with the main themes of this book, especially the concept of "soul," which Moore is careful to distinguish from "spirit." In preparing to write this book, Moore spent two years visiting hospitals and interviewing staff and patients. Much of what he saw disturbed him; Care of the Soul in Medicine is described as "Moore's vision for improving health care."

Improving health care is an ambitious goal and a complicated process, as US President Barak Obama is dis- prescriptive, with suggestions on everything from how to decorate waiting rooms to how to communicate with patients. These suggestions range from concrete tips, such as lowering telephone volumes to make units quieter, to more esoteric notions, like treating the sores in a patient's mouth with an awareness that "the mouth has memories of sucking the mother's breast" (how does one do that?). The shift between these approaches is not always smooth and some of Moore's ideas, for example about chakras and how life issues focus in points on the body, are probably so far outside of mainstream medicine that he will lose some readers on the spot.

Moore also has lots of characterbuilding advice for health care professionals, repeatedly suggesting that they should meditate, pray and otherwise cultivate their spirituality. He often disapproves of how we treat our patients and each other, and wants the reader to aspire to be "a better person." "You are a devotee, a suppliant of Apollo, Asklepios, Hygeia, the Lapis Lazuli Radiant Buddha, Jesus the Healer, and Quan Yin," he writes, while also commenting, apparently without irony, that "Medicine especially has an annoying tendency toward moralism."

It's too bad Moore doesn't spend more time doing what he does best, which is finding interesting and somewhat enigmatic associations between mythology, psychology, spirituality and the external world.

Still, many of his observations are insightful and thought-provoking. I had never thought of hospital information desks as establishing liminality, and yes, the receptionist probably does represent the archaic ritual figure of threshold guardian. A model of the heart in a doctor's office becomes an object of contemplation, not merely instruction. And there is a chapter on hospital food that was a delight to read.

Perhaps this book is aiming for too broad an audience. Moore might have been able to expand on the deeper themes he has identified within the culture of medicine if he had chosen to simply explore the hidden dynamics and constructs of the health care system, instead of trying to reform it.

\section{Lara Hazelton MD \\ Psychiatrist}

Halifax, NS 